\title{
Vignette for V13N1 issue
}

\author{
Importance of blood cellular genomic profile \\ in coronary heart disease
}

Arsenic trioxide has been successfully used in patients with relapsed or refractory acute promyelocytic leukemia (APL). Studies have shown that arsenic trioxide induces apoptosis in a variety of cancer cells in vitro. Possible mechanisms for arsenic trioxide-induced apoptosis have been proposed including induction of reactive oxygen species or apoptotic signals or block of antiapoptotic pathway [1, 2]. Huang et al. [3] reported that arsenic trioxide could modulate expression of cell cycle inhibitor $\mathrm{p} 21$ gene through activation of ERK1/2 and JNK in A431 cells. Interestingly, activation of ERK1/2 and JNK seem to regulate p21 promoter activity in an opposite way in A431 cells. Whether we can employ JNK inhibitor to enhance cytotoxicity of arsenic trioxide in vivo remains to be carefully examined.

Enhanced nuclear factor-kappa B-associated Wnt-1 expression in hepatitis B- and C-related hepatocarcinogenesis: identification by functional proteomics

Human hepatitis B and $\mathrm{C}$ viruses ( $\mathrm{HBV}$ and $\mathrm{HCV}$ ) can cause both acute and chronic hepatitis and hepatocellular carcinoma (HCC). Evidence indicates that both $\mathrm{HBV}$ and $\mathrm{HCV}$ can induce the activation of $\mathrm{NF}-\kappa \mathrm{B}$. The constitutive activation of $\mathrm{NF}-\kappa \mathrm{B}$ has often been observed in cancer tissues of HBV-positive HCC [4]. The essential role of $\mathrm{NF}-\kappa \mathrm{B}$ in promoting the development of $\mathrm{HCC}$ from inflammatory hepatitis in a mouse model has recently been demonstrated [5]. Lee et al. demonstrated that Wnt-1 protein was associated with $\mathrm{NF}-\kappa \mathrm{B}$, and $\mathrm{NF}-\kappa \mathrm{B}$-associated Wnt-1 protein was over-expressed in both $\mathrm{HBV}$ - and HCV-related HCC tumor tissues by functional proteomics [6]. These results suggest that enhanced expression of NF- $\kappa \mathrm{B}$-associated Wnt-1 protein may be a mechanism of HBV- and HCV-related hepatocarcinogenesis.

\section{Effect of $\beta$ TCP filled polyetheretherketone on osteoblast cell proliferation in vitro}

The polymers used for ideal bone replacement require important properties such as sufficient strength and stiffness, biocompatibility and longterm stability. One of such polymers, Polyetheretherketone (PEEK), has been used in a wide range of medical applications such as spinal cages and hip prosthesis. However, the employment of PEEK alone may not provide a sufficient interface between implant surface and bone. Calcium phosphate compounds such as $\beta$-tricalcium phosphate ( $\beta$ TCP) have long been considered as bone substitutes. In this current issue, Petrovic et al investigates the potential PEEK composites containing different concentrations of $\beta$ TCP as possible bone analogue substitutes [7]. They found that pure PEEK, is non-toxic, whereas osteoblast cell proliferation was progressively inhibited by the incorporated $\beta$ TCP.

\section{Mesenchymal stem cells and acute myocardial Infarction}

Cardiovascular disease is the leading cause of mortality in developed countries. The prognosis and quality of life for patients with severe ischemic cardiovascular disease are poor. Modern interventional and surgical therapies are not suitable for many of them because the anatomic extent and distribution of arterial occlusion are too severe. The need for alternative treatment strategies is compelling. Stem cell therapies hold promise for the treatment of ischemic cardiovascular disease [8, 9]. Both stem cell therapy and angiogenic growth factor gene therapy have been applied to animal studies and clinical trials. Little is known about the direct comparison between cell therapy and angiogenic growth factor gene therapy. The goal of this study was to compare the effects of human bone marrow-derived mesenchymal stem cells (hMSCs) transplantation [10] and injection of angiogenic 
growth factor genes in a model of acute myocardial infarction in mice. Results demonstrated that hMSCs transplantation was better in decreasing left ventricular end-diastolic dimension and increasing fractional shortening than Ang1 or VEGF gene therapy. Capillary density was more significantly increased after hMSCs transplantation than Ang1 and VEGF gene therapy. In conclusion, intramyocadial transplantation of hMSCs improves cardiac function after acute myocardial infarction through enhancement of angiogenesis and myogenesis in the ischemic myocardium. hMSCs are superior to angiogenic growth factor genes for improving myocardial performance in the mouse model of acute myocardial infarction. Transplantation of hMSCs may become the future therapy of choice for acute myocardial infarction for myocardial regeneration. [11]

\section{Modular organization of SARS coronavirus nucleocapsid protein}

Coronavirus research has gained broad interest after the identification of a new coronavirus as the etiological agent of severe acute respiratory syndrome or SARS [12]. The SARS nucleocapsid protein $(\mathrm{N})$ is abundantly present in infected cells. It binds the viral RNA genome and forms the ribonucleoprotein core of virion particles. $\mathrm{N}$ protein is also a major antigen, an attribute used in rapid-diagnosis kits against SARS. Chang et al. [13] now present a mixture of experimental approaches and bioinformatics analyses to describe the structure of SARS $\mathrm{N}$ protein. A two-domain structure is proposed that also appears to be adopted by the $\mathrm{N}$ protein of other coronaviruses. This structural insight opens new venues for the study of these proteins on a domain basis, including the description of interaction partners.

\section{Comparison of tir from enterohemorrahgic and enteropathogenic Escherichia coli strains: two homologues with distinct Intracellular properties}

Tir of enteropathogenic Escherichia coli (EPEC) or enterohemorrahgic E. coli (EHEC) is translocated by a type III secretion system to the host cell membranes. EPEC Tir is phosphorylated at
Tyr474, which is required for the signaling of pedestal formation [14] while Tir of EHEC has no equivalent phosphorylation site but it is similarly needed for cytoskeleton rearrangement. By studying their intrinsic differences, actin in complexes were pelleted down from the lysate of cells expressing EHEC Tir but not EPEC Tir. EHEC Tir was frequently found in fibrous structures whereas EPEC Tir was observed completely in a diffuse form. Tir fibrous formation was mapped to the C-terminal region of EHEC Tir that deviates from the EPEC counterpart, which utilizes an alternative route different from Tyr474 phosphorylation to transduce signals [15].

\section{Neuroprotective effect of a beverage component}

1,2,4-Benzenetriol (BT) detected in the instant coffee has a structure that coincides with a sesame lignan, sesamol [16]. Treatment of mice with BT (25 mg/kg) for three days, at dose that impairs hematopoiesis, sensitizes bone marrow leukocytes to enhance NO production in response to lipopolysaccharide (LPS) [17]. Hou et al. [18] therefore investigated the neuroprotective effect of BT in vitro and in vivo. BT dose-dependently attenuated nitrite production and iNOS mRNA and protein expression in LPS-stimulated murine BV-2 microglia. The neuroprotective effect of BT was further demonstrated in the focal cerebral ischemia model of rats, indicating that it is able to protect neuron from ischemic injury.

\section{Antineural antibody in patients with Tourette's syndrome and their family members}

It has been proposed that antineural antibodies are present in patients with Tourette's syndrome (TS) and other neuropsychiatric disorders. In the current issue, Yeh et al. [19] investigated the presence of antineural antibodies in the individuals with TS and the family members of TS patients. They found that there were prominent antineural antibodies present in TS patients and their first-degree family members, but not in the control group. Their findings imply the importance of genetic vulnerability in the immunological pathophysiology of Tourette's syndrome. 
Opposite effect of ERK1/2 and JNK on p53-independent p21WAF1/CIP1 activation involved in the arsenic trioxide-induced human epidermoid carcinoma A431 cellular cytotoxicity

Regulatory role of various nuclear receptors, including liver X receptor (LXR) and peroxisome proliferator activated receptors (PPARs) involved in lipid metabolism, have been intensively studied [20]. To delineate the events related to hyperlipidemia and atherosclerosis at the level of gene expression, microarray analysis has been performed in transgenic mouse models to highfat feeding. Results showed a major role of nuclear receptors in the simultaneous regulation of lipid and inflammatory genes [21]. Baba et al. [22] examined the level of transcriptional expression of genes coding for PPARs $(\alpha, \gamma)$, CD36, LXR $\alpha$ and low density lipoprotein receptor (LDLR) in blood mononuclear cells as blood cellular genomic expression profile. They then studied the interrelationship between blood cellular genomic expression profile, serum lipid levels and severity of coronary heart disease (CHD) in human subjects. Although blood cellular genomic expression of PPARs $(\alpha, \gamma)$, CD36, LDLR showed positive correlation with the severity of coronary atherosclerosis, blood cellular LXR $\alpha$ genomic profile showed negative correlation with the severity of coronary atherosclerosis in subjects with or without hypercholesterolemia. They suggested that blood cellular LXR $\alpha$ has a protective effect against the development of CHD and hence may be of importance in devising synthetic therapeutic drugs for CHD in the future.

Taxifolin ameliorates cerebral ischemia-reperfusion injury in rats through its anti-oxidative effect and modulation of NF-kappa $B$ activation

Ischemic reperfusion injury triggers the overproduction of inflammatory cytokines, leukocytes and reactive oxygen/nitrogen species leading to tissue damage [23, 24]. Cerebral ischemia reperfusion has been used widely as a model to mimic ischemic stroke-induced brain injury [24, 25]. Taxifolin, a flavonoid with a structure related to that of quercetin, has been shown to ameliorate cerebral infarct as induced by middle cerebral artery occlusion followed by reperfusion in adult rats.
Administration of taxifolin reduced the size of infarct in the brain. Taxifolin also inhibited leukocyte infiltration and production of reactive oxygen/nitrogen species (including cyclooxygenase, nitric oxide synthase) in brains injured by cerebral ischemia reperfusion [24]. Nuclear transcriptional factor-kappa B (NF- $\mathrm{KB})$ plays a key role in mediating oxidative stress-induced cell injury and is an indicator that signals up-regulation of inflammatory proteins [23, 26, 27]. The enhanced activity of NF- $\kappa \mathrm{B}$ triggered by cerebral ischemia reperfusion was also inhibited by taxifolin, indicating that the antioxidative effect of taxifolin is mediated at least in part via the reduction of NF$\mathrm{kB}$ activation .

\section{Hyperbaric oygen induces VEGF expression through ERK, JNK and c-Jun/AP-1 activation in human umbilical vein endothelial cells}

Hyperbaric oxygen (HBO) is beneficial in treating ischemia-related wounds. However, the mechanism for HBO-induced vessel formation is still unclear. Vascular endothelial growth factor (VEGF) is the most critical driver of angiogenesis, which plays an important role in wound healing [28]. Lee et al. [29] demonstrated that $\mathrm{HBO}$ induced the expression of VEGF in human umbilical vein endothelial cells (HUVECs). The HBO-induced VEGF expression is through the binding of activated AP-1 to the AP1 sites of VEGF promoter.

\section{References}

1. Miller W.H. Jr., Schipper H.M., Lee J.S., Singer J. and Waxman S., Mechanisms of action of arsenic trioxide. Cancer Res. 62: 3893-3903, 2002.

2. Zheng P.Z., Wang K.K., Zhang Q.Y., Huang Q.H., Du Y.Z., Zhang Q.H., Xiao D.K., Shen S.H., Imbeaud S., Eveno E., Zhao C.J., Chen Y.L., Fan H.Y., Waxman S., Auffray C., Jin G., Chen S.J., Chen Z. and Zhang J., Systems analysis of transcriptome and proteome in retinoic acid/arsenic trioxide-induced cell differentiation/apoptosis of promyelocytic leukemia. Proc. Natl. Acad. Sci. USA 102: 7653-7658, 2005.

3. Huang H.S., Liu Z.M., Ding L., Chang W.C., Hsu P.Y., Wang S.H., Chi C.C. and Chuang C.H. Opposite effect of ERK1/2 and JNK on p53-independent p21WAF1/CIP1 activation involved in the arsenic trioxide-induced human epidermoid carcinoma A431 cellular cytotoxicity. J. Biomed. Sci. (this issue). 
4. Block T.M., Mehta A.S., Fimmel C.J. and Jordan R., Molecular viral oncology of hepatocellular carcinoma. Oncogene 22: 5093-5107, 2003.

5. Pikarsky E., Porat R.M., Stein I., Abramovitch R., Amit S., Kasem S., Gutkovich-Pyest E., Urieli-Shoval S., Galun E. and Ben-Neriah Y., NF-kappaB functions as a tumour promoter in inflammation-associated cancer. Nature 431: 461-466, 2004.

6. Lee T.H., Tai D.I., Cheng C.J., Sun C.S., Lin C.Y., Sheu M.J., Lee W.P., Peng C.Y., Wang A.H.J. and Tsai S.L. Enhanced nuclear factor-kappa B-associated Wnt-1 expression in hepatitis B- and C-related hepatocarcinogenesis: identification by functional proteomics. J. Biomed. Sci. (this issue).

7. Petrovic L., Pohle D., Munstedt H., Rechtenwald T., Schegel K.A. and Rupprecht S. Effect of $\beta$ TCP filled polyetheretherketone on osteoblast cell proliferation in vitro. J. Biomed. Sci. (this issue).

8. Weissman I.L., Translating stem and progenitor cell biology to the clinic: barriers and opportunities. Science 287: 1442-1446, 2000.

9. Fukuda D., Development of regenerative cardiomyocytes from mesenchymal stem cells for cardiovascular tissue engineering. Artif Organs 25: 187-193, 2001.

10. Orlic D., Hill J.M. and Arai A.E., Stem cell for myocardial regeneration. Circ. Res. 91: 1092-1102, 2002.

11. Rafii S. and Lyden D., Therapeutic stem and progenitor cell transplantation for or gan vascularization and regeneration. Nat. Med. 9: 702-712, 2003.

12. Lai M.M., SARS virus: the beginning of the unraveling of a new coronavirus. J. Biomed. Sci. 10: 664-675, 2003.

13. Chang C.K., Sue S.C., Yu T.H., Hsieh C.M., Tsai C.K., Chiang Y.C., Lee S.J., Hsiao H.H., Wu W.J., Chang W.L., Lin C.H. and Huang T.H. Modular organization of SARS coronavirus nucleocapsid protein. J. Biomed. Sci. (this issue).

14. DeVinney R., Stein M., Reinscheid D., Abe A., Ruschkowski S. and Finlay B.B., Enterohemorrhagic Escherichia coli O157:H7 produces Tir, which is translocated to the host cell membrane but is not tyrosine phosphorylated. Infect. Immun. 67: 2389-2398, 1999.

15. Chuang C., Chiu H., Hsu S., Ho J. and Syu W. Comparison of Tir from Enterohemorrahgic and Enteropathogenic Escherichia coli strains: two homologues with distinct intracellular properties. J. Biomed. Sci. (this issue).

16. Hiramoto K., Li X., Makimoto M., Kato T. and Kikugawa $\mathrm{K}$., Identification of hydroxyhydroquinone in coffee as a generator of reactive oxygen species that break DNA single strands. Mutat. Res. 419: 43-51, 1998.

17. Laskin J.D., Rao N.R., Punjabi C.J., Laskin D.L. and Synder R., Distinct actions of benzene and its metabolites on oxide production by bone marrow leukocytes. J. Leukoc. Biol. 57: 422-426, 1995

18. Hou C.W., Chen Y.S., Chen C.H., Chen Y.H. and Jeng K.C. Protective effect of 1, 2, 4-benzenetriol on LPS- induced NO production by BV2 microglial cells. J. Biomed. Sci. (this issue).

19. Yeh C.B., Wu C.H., Tsung H.C., Chen C.W., Shyu J.F. and Leckman J.F. Antineural antibody in patients with Tourette's syndrome and their family members. J. Biomed. Sci. (this issue).

20. Chawla A., Repa J.J., Evans R.M. and Mangelsdorf D.J., Nuclear receptors and lipid physiology: opening the X-files, Science 294: 1866-1870, 2001.

21. Kreeft A.J., Moen C.J.A., Porter G., Kasanmoentalibc S., Sverdlov R., Gorp P.J., Havekes L.M., Frants R.R. and Hofker M.H., Genomic analysis of the response of mouse models to high-fat feeding shows a major role of nuclear receptors in the simultaneous regulation of lipid and inflammatory genes. Athreosclerosis 182: 249-257, 2005.

22. Baba M.I., Kaul D. and Grover A. Importance of blood cellular genomic profile in coronary heart disease. J. Biomed. Sci. (this issue).

23. Hung L.M., Wei W., Hsueh Y.J., Chu W.K. and Wei F.C., Ischemic preconditioning ameliorates microcirculatory disturbance through downregulation of TNF-alpha production in a rat cremaster muscle model. J. Biomed. Sci. 11: 773-780, 2004.

24. Wang Y.H., Wang W.Y., Chang C.C., Liou K.T., Sung Y.J., Liao J.F., Chen C.F., Chang S., Hou Y.C., Chou Y.C. and Shen Y.C. Taxifolin ameliorates cerebral-reperfusion injury in rats through its anti-oxidative effect and modulation of NF-kappa B activation. Biomed. Sci. (this issue).

25. Chen S.H. and Cheung R.T.F., Neuropeptide Y and its receptor analogs differentially modulate the immunoreactivity for neuronal or endothelial nitric oxide synthase in the rat brain following focal ischemia with reperfusion. J. Biomed. Sci. 12: 267-278, 2005.

26. Chen H.C., Lin H.C., Liu C.Y., Wang C.H., Hwang T., Huang T.T., Lin C.H. and Kuo H.P., Neutrophil elastase induces IL-8 synthesis by lung epithelial cells via the mitogen-activated protein kinase pathway. J. Biomed. Sci. 11: 49-58, 2004.

27. Lin C.C., Sun C.C., Luo S.F., Tsai A.C., Chien C.S., Hsiao L.D., Lee C.W., Hsieh J.T. and Yang C.M., Induction of cyclooxygenase-2 expression in human tracheal smooth muscle cells by interleukin-1beta: involvement of p42/p44 and p38 mitogen-activated protein kinases and nuclear factor-kappaB. J. Biomed. Sci. 11: 377-390, 2004.

28. Yancopoulos G.D., Davis S., Gale N.W., Rudge J.S., Wiegand S.J. and Holash J., Vascular-specific growth factors and blood vessel formation. Nature 407: 242-248, 2000.

29. Lee C.C., Chen S.C., Tsai S.C., Wang B.W., Liu Y.C., Lee H.M. and Shyu K.G. Hyperbaric Oxygen Induces VEGF Expression through ERK, JNK and c-Jun/AP-1 Activation in Human Umbilical Vein Endothelial Cells. J. Biomed. Sci. (this issue). 